\title{
Logistical Activities in the Function of Development of the Shipbuilding Industry
}

\author{
Tatjana Stanivuka , Marko Šundov ${ }^{b}$, Jelena Žanić Mikuličića, \\ Antonija Mišuraa
}

This paper examines the impact of supply on production results in the shipbuilding industry. The shipbuilding industry is characterized by extreme complexity, as the integration of many other industries is required, and the industry's product itself is highly complex and expensive, requires a high degree of processing and subsequently yields significant revenue. Since numerous suppliers are involved in the production process, shipbuilding has a multiplicative effect on other industries. Logistics are one of the fundamental factors for the industry's efficient and effective operation. Supply is considered in this paper as it is nowadays a strategic decision that actively influences business success in the shipbuilding industry. The purpose of the simulation of its impact on the production process is the avoidance of possible mistakes that could not only weaken a company's competitive position, but endanger its viability as well. The simulation ends with a concrete example illustrating

\section{KEY WORDS}

$\sim$ Shipbuilding industry,

$\sim$ Logistics,

$\sim$ Simulation,

$\sim$ Time deviation

a. University of Split, Faculty of Maritime Studies, Split, Croatia

e-mail: tstanivu@pfst.hr

b. Stano-uprava d.o.o., Split, Croatia

e-mail: markosundov2@gmail.com

doi: 10.7225/toms.v09.n01.004

This work is licensed under (cc) BY that time deviations (arrivals, withdrawal and complaints) increase the basic value of the order to a certain extent. This paper highlights the need to maximize the speed of response to customer needs through the synthesis of planning activities and business logistics, and to remain competitive in an increasingly demanding global market.

\section{INTRODUCTION}

Maritime economy consists of shipbuilding, fishing, the exploitation of the sea and seabed mineral resources, production industry, shipping, seaports, coastal tourism and various maritime services (maritime agencies, shipping banks, insurance etc.) (Žuvela, 2000). Shipbuilding is an intensive activity that requires the application of modern technology and encourages innovation in the production process, as a key factor of competitiveness that helps reduce costs (Kersan-Škabić, 2009). Although shipbuilding industry is the most important industry in all maritime countries, the shipbuilding market is characterized by fluctuations of supply and demand on the global level and large cyclical fluctuations in the shipbuilders' financial operations (Pašalić, 1996). One of the key factors for achieving efficiency and effectiveness in maritime and economic systems, and thus in the shipbuilding industry, are maritime logistics that enrich, integrate and validate the profiled structure of transport and economic systems (Zelenika, 2002). The ship, as the main product of the shipbuilding industry, is a highly complex and expensive product. It requires a high degree of processing, which subsequently yields significant revenue and has a multiplicative effect on other industries.

In general, shipyards are organized functionally, with the manufacturing sector organized by production stages. This 
organizational structure, where shipyards strive to maintain a continuous production process with fixed production capacity is characteristic of Far Eastern shipbuilders (Perić Hadžić et al., 2013). However, the ultimate goal is to improve the end product by enhancing all elements of the value chain, which is defined as "a combination of nine generic activity values which result in a joint action by delivering the value to customers" (Porter, 1985). Nine generic security activities of the company are input logistics, operations, output logistics, marketing and sales, service, infrastructure companies, human resource management, research, technology and system development and procurement (Porter, 1985). All indicated activities are important in the planning stage as the key determinant of a shipyard's success. The intention is to create a solid basis for increasing business logistics efficiency. The efficient resolution of logistical problems in shipyards not only involves service minimization or maximization, but a compromise between these goals as well.

Coordination at the level of construction (project) technology - supply is required as a prerequisite for achieving a high level of interaction between organizational elements: plan -construction-technology (PCT), supply and production. Owing to the variable nature of business structure and flows, supply is a key factor in the process of connecting and creating virtual structures (Segetlija, 2008). Thus, the sales value of the ship, as the product of the shipbuilding industry, confirms the importance of supply activities in the value chain. As improvement is becoming increasingly important in the shipbuilding industry, shipyards are seeking to improve the process of evaluation of the current state of their manufacturing process to stay competitive (Ozkok, 2013), and this process is largely related to supply. The economic efficiency of supply is measured on the basis of the value of generated effects and acquisition costs (Buntak et al., 2014). In line with the above, the topic of this paper are supply activities in the shipbuilding industry, with a simulation of their impact on the manufacturing process in the respective industry. The assumption was that greater flexibility and coherence of tactical and operational level planning create higher added value within the shipbuilding process through better management of business logistics. Simulation procedure was used as a way to manage product lifecycle to facilitate production planning or decision-making (Back et al., 2016). Simulation is a tool especially useful in the shipbuilding industry.

\section{ROLE OF LOGISTICAL ACTIVITIES IN THE SHIPBUILDING INDUSTRY}

The ship, as the final product of the shipbuilding industry, is extremely complex and specific, as it requires a large number of inputs, materials and equipment. The production process is time-consuming and consists of a large number of processes and sub-processes using many different technologies.
The customer, who appears at the very beginning of the process, plays an important role in the creation of this product. The buyer not only participates in the construction of the vessel financially, but is also very knowledgeable and seeks the highest quality fulfilment of his requirements. Consequently, buyers evidently have an active role in the supply of inputs necessary for production, and the complex relationship between the buyer and the supplier is illustrated in Figure 1. The basic interest of the buyers is to have their needs met at the lowest possible cost, while maintaining the functionality of all production processes without compromising the standard of the final product. The preconditions for success are thereforetactand optimization of the entire supply chain, combined with effective intra-organizational flexibility. In this context, the speed of an enterprise's response to change, which defines a company's performance, should not be neglected, since the factors and forces from the macroenvironment of the company, which have the greatest influence on the formulation of the business strategy, usually relate to the immediate industrial and competitive environment (Thompson et al., 2008).

However, one of initial activities in the process of transformation of raw materials into finished products is planning, which must be flexible enough to accommodate any changes in the micro and macro environment. The efficiency of logistics of supply (LN) and logistics of production (LP) can be measured by various parameters. One of the most obvious and cost-effective parameters in shipbuilding is supply status, i.e. flow or turnover. In production activities like shipbuilding providing quality to the customer is directly related to the level of purchased material inputs.

Supply status, i.e. the status of delivery logistics, is indicative of the level of a shipyard's planning flexibility. There is certain coherence between activities within the organization and activities that precede or follow them. Otherwise, the causes of dysfunction in the process must be recorded and eliminated. When making a business logistics efficiency model, the following factors should be taken into consideration:

- level planning (flexibility of tactical and operational planning)

- $\quad$ supply logistics (SL)

- $\quad$ supply status

- $\quad$ production logistics (LP)

There should be an interconnection between two variables contained in the above-mentioned factors. The first variable independently constitutes the level of planning, i.e. the degree of flexibility between tactical and operational level planning. The second variable is business logistics efficiency, i.e. the synthesis of supply logistics (SL) and production logistics (LP), the indicator being supply status. The direct link between the indicator and flexibility planning activities (tactical and operational) confirms the basic hypothesis of this paper. All three levels (orders, supply, 
activity) illustrated in Figure 2 are directly influenced by the flexibility of the planned level. Optimizing the interrelations of these levels, i.e. reducing costs while keeping process continuity at a competitive level, is paramount.

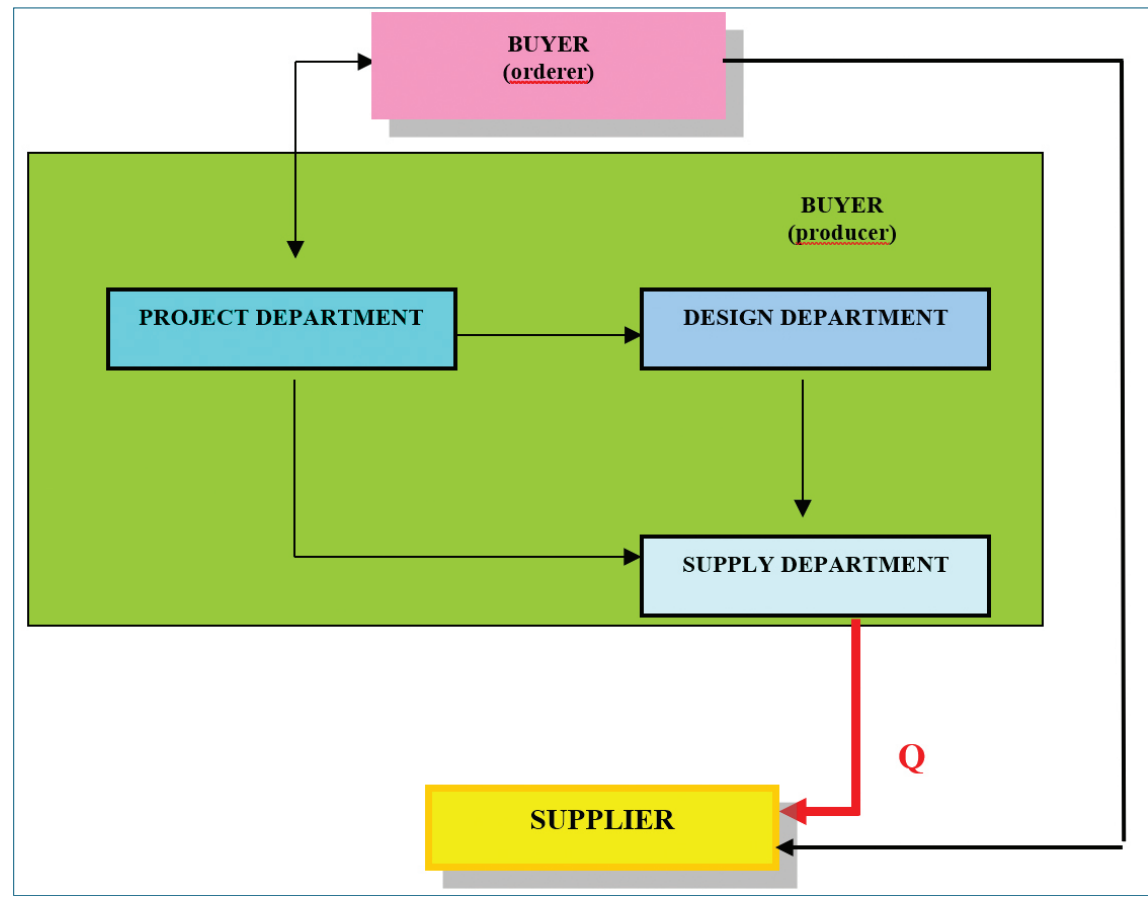

Figure 1.

Customer-supplier relationship in the shipbuilding production proces (Source: Authors).

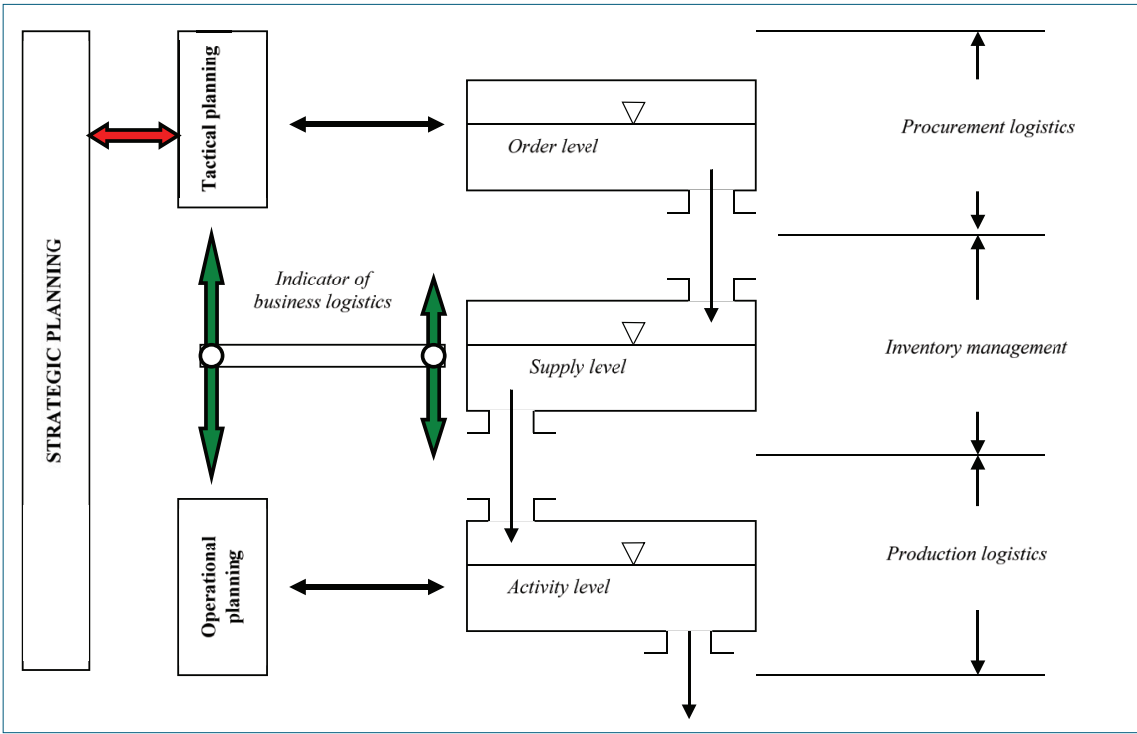

Figure 2 .

Connection of flexibility of planning levels with the efficiency of business logistics (Source: Authors). 


\section{SIMULATION OF THE IMPACT OF THE SUPPLY PROCESS ON THE PRODUCTION SYSTEM IN THE SHIPBUILDING INDUSTRY}

In the shipbuilding industry, the functionality of the logistics chain is key to achieving good business results. To make better business decisions and minimize any mistakes potentially detrimental to business, managers use a variety of support tools. The development of information and communication technology has made a major step forward in enterprise management methods (Lee et al., 2014). Various forms of simulations are commonly used by managers from all industries, including the shipbuilding industry. Simulating events is often the only way to predict future mistakes. This paper presents a simulation of the impact of supply on production system costs, on the example of Brodotrogir Shipyard. The model correlates time deviations in the material supply chain (receipt time - XDP, withdrawal - XDI, complaint time - XDR) with cost and product value (PV). The development of the final computer simulation model requires certain steps to be made, which largely determine the accuracy of the values shown. In this context, the systematic - dynamic simulation model should answer the following question: Does the decrease or increase in time deviations in the material purchase chain have an impact on the value of the product itself (Figure 3). The analysis of potential improvement of competitiveness through cost reduction is conducted on the selected segment of the value chain.

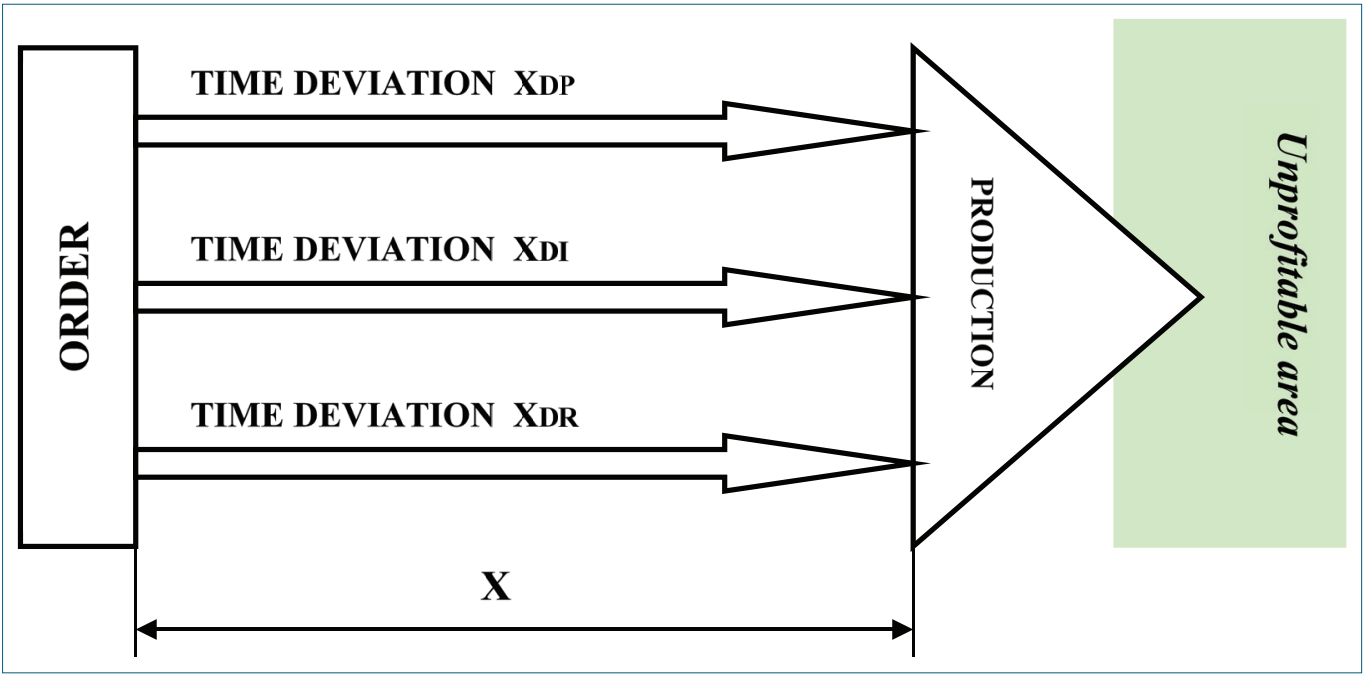

Figure 3.

Impact of time deviations in the material purchase chain on product value (Šundov, 2009).

Purchase is a complex process that can be viewed from different perspectives, i.e. purchase status can be recorded by tracking orders or order segments. Thereby, by gaining an understanding of time deviations (XDP, XDI, XDR), we have attempted to express their impact on the value of the product - ship (ZB) through costs. The model required the issue of the manner of expression of time deviations in terms of costs to be resolved. In addition, the simulation model had to establish a connection between temporal and financial aspects, and present them in an acceptable manner. The focus is on the buyer-supplier relationship. The model is primarily a tool for rapid detection of possible dysfunctionalities in the supply process. The first step after the analysis of the current state of the purchasing process in a shipbuilding system such as Brodotrogir is the development of linear simulation. Statistical data obtained by analyzing eighty orders and tracking time deviations during their realization were used in simulation development. By analyzing and processing the mentioned orders, the basic statistical order distribution indicators according to three-time deviations were calculated (Table 1). The mean receipt time deviation is 65 days, with the mean deviation of 55.46. The mean withdrawal time deviation is 71 days, with the mean deviation of 57.41 . The mean complaint time deviation is 17 days, with the mean deviation of 48.33 .

Mean deviation of withdrawal time was observed to be the highest and have the highest standard deviation. Yet, the model suggests that the highest receipt time and complaint time deviation is zero (the modal value for receipt time is not representative because 7 out of 80 orders have 0 deviation, whereas in case of complaint time as many as 67 out of 80 orders have 0 time deviation). Positive skewness values indicate that order distribution is skewed to the right for all time deviations. Besides, positive kurtosis values show that peak distributions 
Table 1.

Descriptive statistical indicator of eighty orders (Šundov, 2009).

\begin{tabular}{llll} 
Time deviations & $X d p$ & $X d i$ & $X d r$ \\
\hline Mean & 65.01 & 70.9375 & 16.93 \\
\hline Standard Error & 6.20 & 6.419051543 & 5.40 \\
\hline Median & 61 & 50 & 0 \\
\hline Mode & 0 & 42 & 0 \\
\hline
\end{tabular}

$\begin{array}{llll}\text { Standard } & 55.46 & 57.4137424 & 48.33\end{array}$

Deviation

\begin{tabular}{llll}
\hline $\begin{array}{l}\text { Sample } \\
\text { Variance }\end{array}$ & 3075.99 & 3296.337816 & 2335.84 \\
\hline Kurtosis & 1.62 & 1.757294151 & 7.64 \\
\hline Skewness & 1.13 & 1.439355606 & 2.96 \\
\hline Range & 257 & 257 & 205 \\
\hline Minimum & 0 & 5 & 0 \\
\hline Maximum & 257 & 262 & 205 \\
\hline Sum & 5201 & 5675 & 1354 \\
\hline Count & 80 & 80 & 80 \\
\hline
\end{tabular}

(most frequently) are around the modal value. In addition to mean values (arithmetic mean, median and mode), standard deviations, skewness and kurtosis measures, Table 1 also shows the highest and lowest values of variables, as well as the variation range. We have obtained the following values from available data:

$Z_{N}=63,696,879(\mathrm{HRK})$ total value of eighty orders

$\bar{X}_{\mathrm{DP}}=65$ (day) .. mean receipt time deviation per order

$\bar{X}_{D I}=71$ (day)....mean withdrawal time deviation per order

$\bar{X}_{D R}=17$ (day)...... mean complaint time deviation per order

The following values were calculated:

ZU...value of total orders increased by mean time deviations

ZS.....value of total orders increased after correcting mean time deviations

Following the analysis of statistical data on eighty orders, we obtained the mean percentage of the linear increase of the basic value. The linear increase is different for individual mean time deviations, and can be expressed as follows:

$\bar{Y}_{P}=0.0043 \times \bar{X}_{D P} \ldots .$. mean percentage of increase in order value

caused by

mean receipt time deviation
$\bar{Y}_{1}=0.0041 \times \bar{X}_{D I} \ldots \ldots$ mean percentage of increase in order value

caused by

mean withdrawal time deviation

$\bar{Y}_{R}=0.0048 \times \bar{X}_{D R} \ldots \ldots$ mean percentage of increase in order value

caused by

mean complaint time deviation

By inserting the known values we obtain:

$\bar{Y}_{p}=0.0043 \times 65=28 \%$

$\bar{Y}_{1}=0.0041 \times 71=29 \%$

$\bar{Y}_{R}=0,0048 \times 17=8 \%$

It follows that:

$Z_{p}=Z_{N} \times \bar{Y}_{p}=63.696879,00 \times 0.28=17.835126,12(\mathrm{HRK})$

$Z_{1}=Z_{N} \times \bar{Y}_{1}=63.696879,00 \times 0.29=18.472094,91(H R K)$

$Z_{R}=Z_{N} \times \bar{Y}_{R}=63.696879,00 \times 0.08=5.095750,32(H R K)$

Therefore, the basic value of order N62 was increased by the following amount:

$Z_{\mathrm{PIR}}=Z_{\mathrm{P}}+Z_{\mathrm{I}}+Z_{\mathrm{R}}=17.835126,12+18.472094,91+5.095750,32$

$=41.402971,35(\mathrm{HRK})$

Total order value is:

$Z_{U}=Z_{N}+Z_{P I R}=63.696879,00+41.402971,35$

$=105.099850,35$ (HRK)

The above indicates that the total mean value of all orders increased by $60 \%$. Simulation of order value fluctuations through the correction of average time deviations in just two days gives the following results:

$$
\begin{aligned}
& \bar{Y}_{P}=0.0043 \times 63=27 \% \\
& \bar{Y}_{1}=0.0041 \times 69=28 \% \\
& \bar{Y}_{R}=0.0048 \times 15=7 \%
\end{aligned}
$$

Furthermore, when previous values are inserted into the known equations we obtain:

$Z_{p}=Z_{N} \times \bar{Y}_{p}=63.696879,00 \times 0.27=17.198157,33(\mathrm{HRK})$

$Z_{1}=Z_{N} \times \bar{Y}_{1}=63.696879,00 \times 0.28=17.835126,12(\mathrm{HRK})$

$Z_{R}=Z_{N} \times \bar{Y}_{R}=63.696879,00 \times 0.07=4.458781,53(H R K)$

Therefore, the total mean order value increased by the following amount due to mean time deviation corrections:

$Z_{\mathrm{PIR}}=Z_{\mathrm{P}}+Z_{\mathrm{I}}+Z_{\mathrm{R}}=17.198157,33+17.835126,12+4.458781,5$ $=39.492064,8$ (HRK) 
If the adjustment of average time deviations causes the reduction of value of total orders, the results are as follows:

$$
\begin{aligned}
& Z_{S}=Z_{N}+Z_{P I R}=63.696879,00+39.492064,98 \\
& =103.188943,98(H R K)
\end{aligned}
$$

The results indicate that significant cost reduction can be achieved and the total value of orders increased by correction of mean time deviations. Total savings for the eighty orders analyzed, with the time correction of two days, are:

$$
\mathbf{Z U}-\mathbf{Z S}=105.099850,35-103.188943,98=1.910906,37
$$
(HRK)

The results obtained by statistical analysis of eighty orders of materials, accounting for $26.88 \%$ of product value, must be analyzed in detail. Owing to such a high share in product value, this sample is relevant for the confirmation or negation of the paper's hypothesis. Table 1 presents variables necessary for purchase process analysis in a manufacturing system such as Brodotrogir. The analysis is based on the well known fact that delays in the delivery of materials create certain costs in the purchase chain, with respect to certified values. However, by defining three time deviations (receipt time XDP, withdrawal time XDI and complaint time XDR), we attempted to examine the efficiency of the purchasing process in a simple manner, by looking into the relationship with the supplier. Cost expressions of three time deviations and connecting them with certain characteristics of the buyer - supplier relationship, may give us a picture of the condition in which the purchasing processes of manufacturing systems such as shipbuilding take place. Figure 4 shows linear dependence of the percentage of total order costs on the number of receipt days. The correlation of positive direction and strong intensity is obvious. Linear dependence between the observed variables is analytically described by a single regression model so as to quantify the average percentage of effect of oneday delay in receipt time on total order cost. The estimated linear regression model with a constant can be expressed as:

$\hat{y}_{i}=26,1+0,2 x$

Parameter and variable $\mathrm{x}$ show that one-day delay in receipt time can be expected to increase order costs by $0.2 \%$. The constant shows that a $26.1 \%$ increase in order costs can be expected if there is no delay in receipt time $(x=0)$, i.e. some order costs must logically be expected even when there is no delay in receipt time, owing to potential delays in withdrawal or complaint time. Figure 4 shows that these orders lie exactly on the ordinate axis. Still, in order to neutralize the impact of withdrawal and complaint time, linear regression without a constant is estimated (regression line going through the origin).

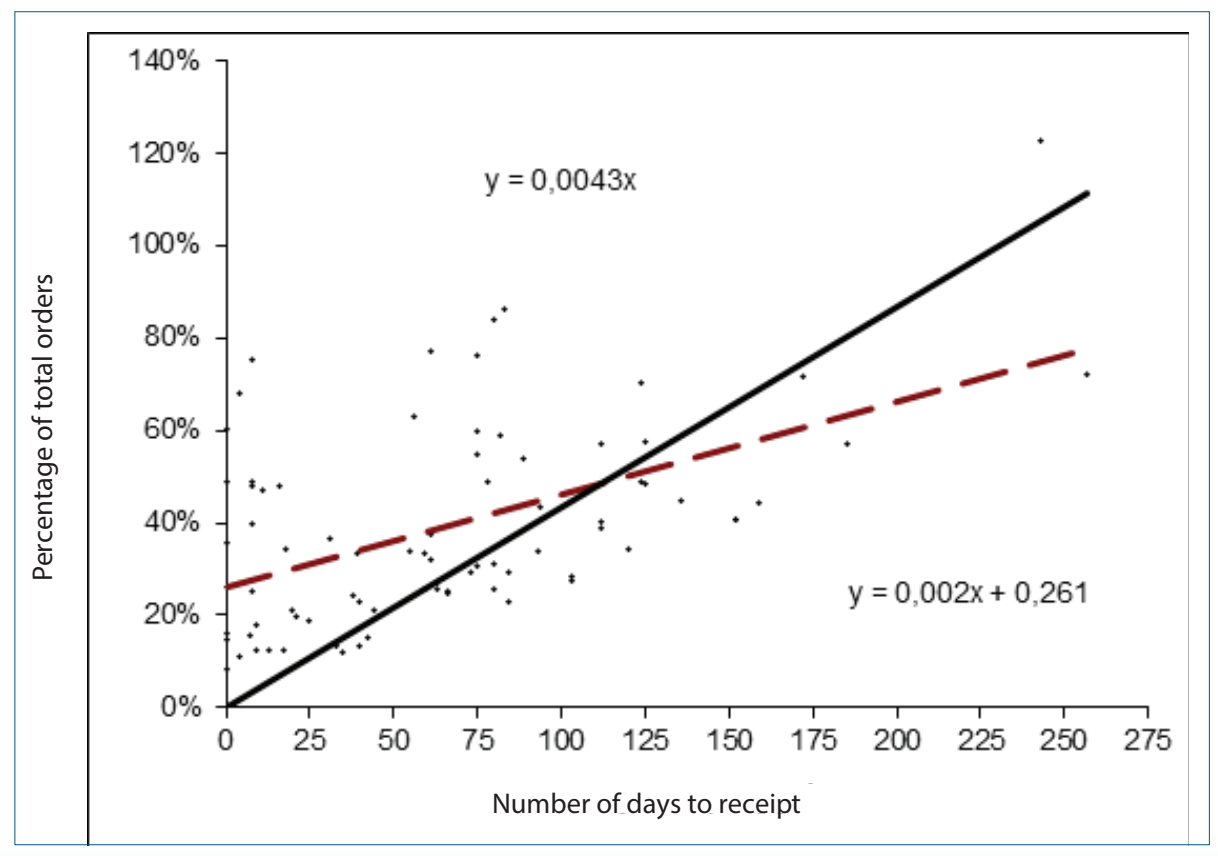

Figure 4.

Scatter plot between the percentage of total order costs and the number of days to receipt (Šundov, 2009). 
Figure 5 shows the linear dependence of the percentage of total order costs on the number of withdrawal time days. The correlation between positive direction and strong intensity is obvious. Linear dependence between the observed variables is analytically described using a single regression model so as to quantify the average percentage of contribution of one-day

$\hat{y}_{i}=26,07+0,18 x_{i}$ delay in receipt time to total order costs. The estimated linear regression model with a constant is as follows:

Parameter and variable $\mathrm{x}$ show that one-day delay in withdrawal time can be expected to increase order costs by 0,18 $\%$. The constant shows that a $26.07 \%$ increase in order costs can be expected if there is no delay in withdrawal time $(x=0)$, i.e. some order costs must be expected even when there is no delay in withdrawal time, owing to potential delays in receipt or complaint time. Figure 5 shows that these orders lie exactly on the ordinate axis.

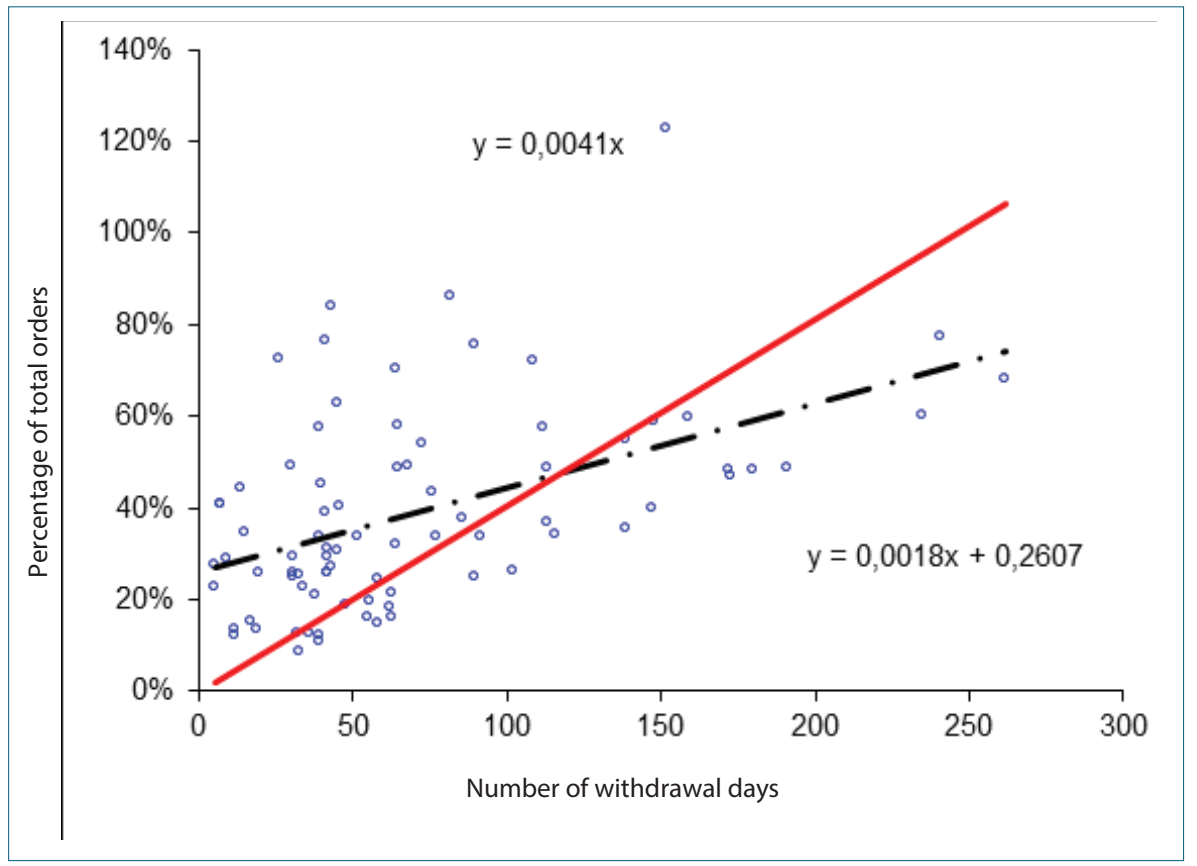

Figure 5.

Scatter plot between the percentage of total order costs and the number of days to withdrawal (Šundov, 2009).

Still, in order to neutralize the impact of receipt and complaint time, linear regression without a constant is estimated (regression line going through the origin). The regression model without a constant was also estimated using SPSS (Statistical Package for Social Sciences) program support. The results of estimation of the defined model using SPSS are given in Table 3. In the first part of Table 2, regression model can be seen to explain $69 \%$ of total deviations in the observed dependent variable (R-square - determination coefficient). The correlation coefficient of $0.831(\mathrm{R})$ confirms positive dependence of strong intensity. The standard error of 24.967 shows that the mean deviation of observed values from the regression line is relatively medium-sized (63\%). The ANOVA (analysis of variance) table indicates high value of empirical F-ratio, implying that the statistical significance of the regression model at the theoretical level is $5 \%$ and $1 \%$. In addition to the F-test (group test), a t-test (individual test) was also conducted, which shows that parameter $B$ (unstandardized coefficient) is also statistically significant since the empirical level of significance is fairly close to zero. A small standard error of 0.031 is indicative of the high value of the test size of 13.266. Finally, parameter B and variable Di show that a $0.407 \%$ increase can be expected for each one-day delay in receipt time, taken together with the neutralized impact of other time deviations. 


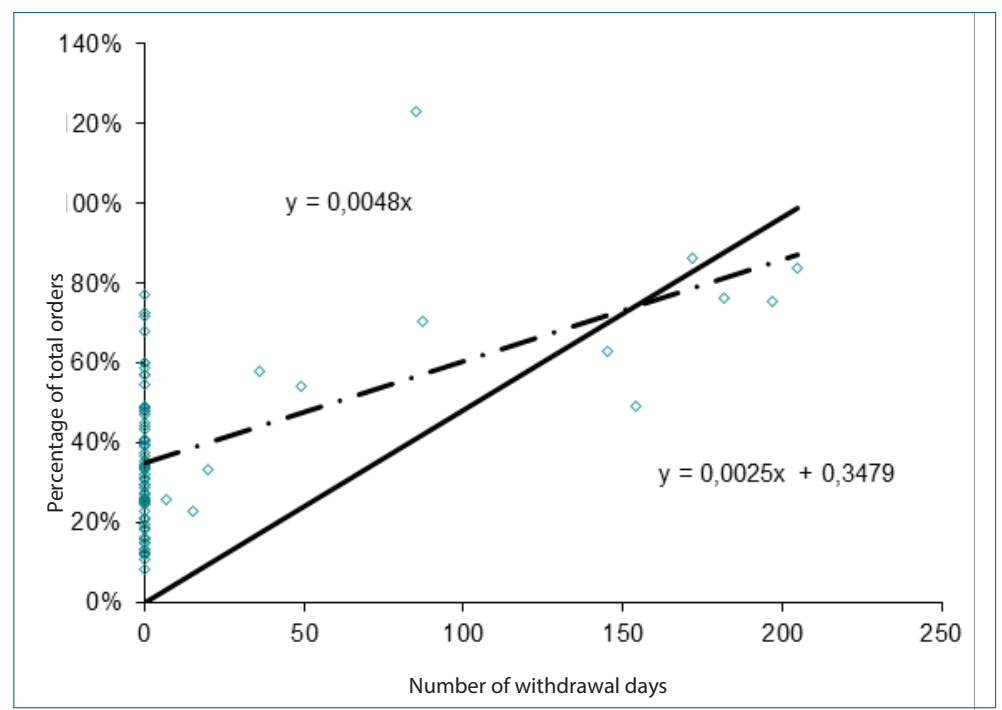

Figure 6.

Scatter plot between the percentage of total order costs and the number of complaint time days (Šundov, 2009).

Table 4.

Regression model estimation and diagnostic tests for time deviations caused by the complaint time (Šundov, 2009).

\section{Model Summary}

\begin{tabular}{lllll}
\hline Model & $\mathrm{R}$ & R Square $^{\mathrm{a}}$ & $\begin{array}{l}\text { Adjusted R } \\
\text { Square }\end{array}$ & $\begin{array}{l}\text { Std. Error of the } \\
\text { Estimate }\end{array}$ \\
\hline 1 &, $550^{\mathrm{b}}$ &, 303 &, 294 & 37,457086 \\
\hline
\end{tabular}

a. For regression throygh the origin (the no-intercept model), R Square measures the proportion of the variability in the dependent variable about the origin explained by regression.

This CANNOT be compared to R Square for models which include an intercept.

b. Predictors: Dp

\begin{tabular}{lllllll}
\hline \multicolumn{9}{c}{ ANOVA $^{\text {c, d }}$} \\
\hline Model & & Sum of Squares & df & Mean Square & F & Sig. \\
\hline 1 & Regression & 48119,821 & 1 & 48119,821 & 34,297 &, $000^{\text {a }}$ \\
\hline & Residual & 110839,631 & 79 & 1403,033 & & \\
\hline & Total & $158959,452^{\mathrm{b}}$ & 80 & & \\
\hline
\end{tabular}

a. Predictors: $\mathrm{Dp}$

b. This total sum of squares is not corrected for the constant because the constant is zero for regression through the origin.

c. Dependent Variable: Post

d. Linear Regression through the Origin

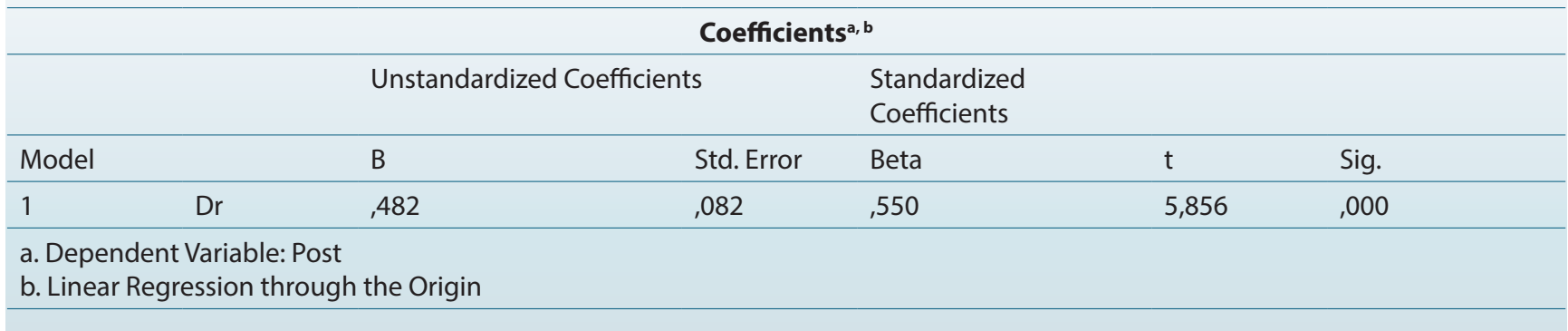


Still, in order to neutralize the impact of receipt and withdrawal time, linear regression without a constant is estimated (regression line going through the origin). The regression model without a constant was also estimated using SPSS (Statistical Package for Social Sciences) program support.

In the first part of Table 4, regression model can be seen to explain $30.3 \%$ of total deviations in the observed dependent variable (R-square - determination coefficient). The correlation coefficient of 0.55 (R) confirms positive dependence of strong intensity. The standard error of 37.457 shows that the mean deviation of observed values from the regression line is relatively medium-sized (71\%). The ANOVA (analysis of variance) table indicates high value of empirical F-ratio, implying that the statistical significance of the regression model at the theoretical level is $5 \%$ and $1 \%$. In addition to the F-test (group test), a t-test (individual test) was also conducted, which shows that parameter $B$ (unstandardized coefficient) is also statistically significant since the empirical level of significance is fairly close to zero. A small standard error of 0.082 is indicative of the high value of the test size of 5.856. Finally, parameter B and variable Dr show that a $0.482 \%$ increase can be expected for each one-day delay in receipt time, taken together with the neutralized impact of other time deviations.

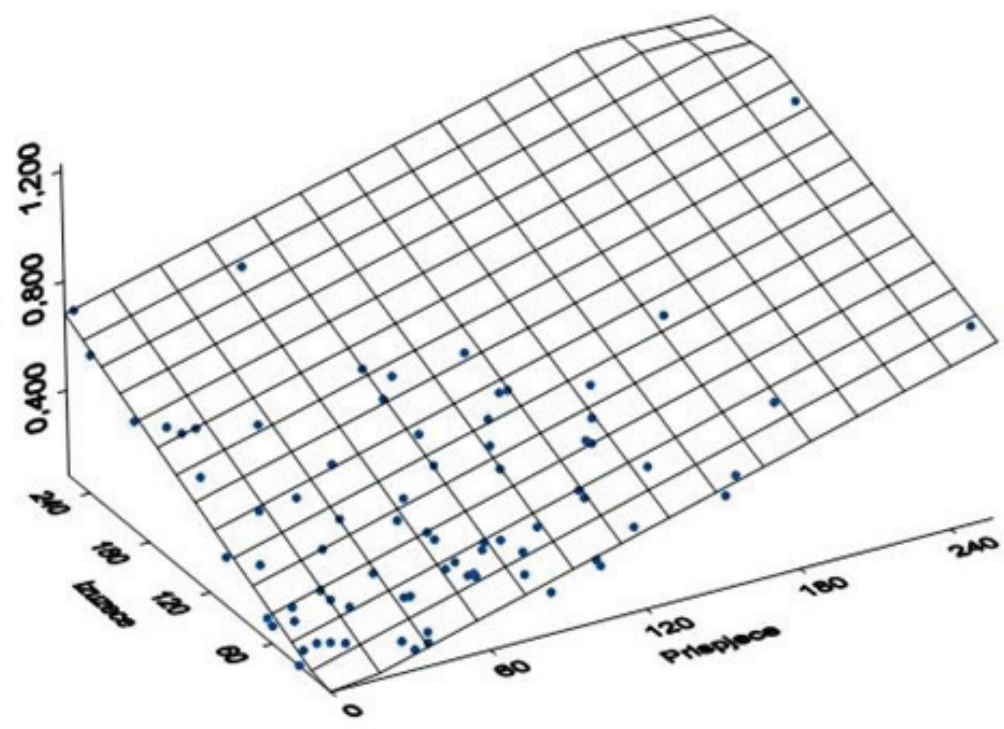

Figure 7.

Three-dimensional representation of order costs depending on receipt and withdrawal time deviations (Šundov, 2009).

The three-dimensional representation (Figure 7) illustrates that order costs are expected to increase when the number of days of order delay increase on account of receipt time simultaneously with the confirmation of withdrawal by the bias of the hyperplane estimated on the basis of original data.

\section{CONCLUSION}

Simulation is a useful tool in the shipbuilding industry whereby modern management seeks to improve the quality of decision-making. The simulation of eighty statistically processed orders of Brodotrogir worth almost HRK 64 million or $26.88 \%$ of total product value, indicates that deviations have great influence (arrivals, withdrawals and complaints). The influence of three mean time deviations is as follows: receipt time of 65 days and $28 \%$, withdrawal time of 71 days and $29 \%$ and complaint time of 17 days and $8 \%$, the total value was increased by $60 \%$. A decrease in time deviations by two days would instantaneously result in savings. The strong impact of receipt and withdrawal time deviations is also evident, whereas the impact of complaint time deviation is significantly smaller. Therefore, activities aimed at improving the factors that have an impact on these two deviations should be strengthened. In the example presented, considerable deviations in arrival (XDP), withdrawal (XDI) and complaint (XDR) times were observed, which significantly affect the profitability and efficiency of the manufacturing process in the shipbuilding industry. Although the reasons for these deviations are different, subjective and objective, there is sufficient room for purchase chain improvement activities. Nevertheless, any competitive organization in the shipbuilding industry must make active supply chain management a priority. One of the activities that transform the purchasing process from 
traditional into strategic is supplier-oriented backward vertical integration. In this way, better cooperation with the supplier has a direct impact on the cost of material inputs, ultimately making the product cheaper. For an immediate buyer - manufacturer knowledge of the value supply chain and its active improvement are the bases for quality positioning on the market. In addition, if the end customer's value chain is known, all the prerequisites for so called category management have been met. By joining these two value chains, immediate manufacturers can ensure timely performance in their production process which will ultimately allow them to remain competitive in the increasingly complex global market such as shipbuilding.

\section{REFERENCES}

Back, M.-G. et al., 2016. A study for production simulation model generation system based on data model at a shipyard. International Journal of Naval Architecture and Ocean Engineering, 8(5), pp. 496-510. Available at: http://dx.doi.org/10.1016/j.ijnaoe.2016.05.005.

Buntak, K., Šuljagić, N., 2014. Economics of Logistics Functions in a Company, Tehnički glasnik, 8(4), pp. 388-393.

Kersan-Škabić, I., 2009. Brodogradnja u europskoj uniji i hrvatskoj- realnost i izazovi, Ekonomska misao i praksa, 2, pp. 373-396.

Lee, J. et al., 2014. Quality Verification of Legacy Data of Manufacturing Information
System to Improve Results of Shipyard Manufacturing Logistics Simulation. Journal of the Society of Naval Architects of Korea, 51(6), pp. 510-520. Available at: http://dx.doi.org/10.3744/snak.2014.51.6.510.

Ozkok, M., Helvacioglu, H.I., 2013. A Continuous Process Improvement Application, Shipbuilding / Brodogradnja, 64, pp. 31-39.

Pašalić, Ž., 1996. Ogledi o maritimnoj ekonomiji Hrvatske, Ekonomski fakultet Split.

Perić Hadžić, A., Karačić, T., 2013. Restrukturiranje hrvatske brodogradnje u kontekstu pristupanja Europskoj Uniji, Naše More, 47-48(1), pp. 121-132.

Porter, M., 1985. Competitive Advantage: Creating and Sustaining Superior Performance, Free press, New York.

Segetlija, Z., 2008. Prikaz knjige Prof. dr. sc. Vilim Ferišak Nabava: Politika - strategija - organizacija - management II, Zagreb, 2002., Str. 617', Ekonomski vjesnik / Review of Contemporary Entrepreneurship, Business, and Economic Issues, 21(1-2), pp.121122.

Šundov, M., 2009. Uloga strateške nabave u povećanju konkurentnosti Hrvatskih brodogradilišta, Magistarski rad, Ekonomski fakultet u Splitu.

Thompson, A. A., Strickland, A.J. and Gamble, J.E., 2008. Strateški menadžment, Mate d.o.o., Zagreb.

Zelenika, R., 2002. Logistika pomorskog gospodarstva - čimbenik afirmacije hrvatskog prometnog i gospodarskog sustava. Naše More, 49(5-6), pp. 197-204. Available at: https://hrcak.srce.hr/120363.

Žuvela, l., 2000. Koncepcija i strategija razvitka pomorskog gospodarstva Hrvatske, Pomorski zbornik, 38(1), pp. 11-60. 